\title{
Evaluation of microvascular network with optical coherence tomography angiography (OCTA) in branch retinal vein occlusion (BRVO)
}

Lulu Chen, Mingzhen Yuan, Lu Sun, Yuelin Wang and Youxin Chen ${ }^{*}$

\begin{abstract}
Background: To evaluate changes of microvascular network of macular and peripapillary regions and to provide a quantitative measurement of foveal avascular zone (FAZ) in unilateral BRVO patients.

Methods: Forty-seven unilateral BRVO patients and forty-seven normal controls were enrolled. A $3 * 3 \mathrm{~mm}$ scan centered on fovea followed by a $4.5^{*} 4.5 \mathrm{~mm}$ scan centered on optic nerve head $(\mathrm{ONH})$ were obtained in BRVO eyes, fellow eyes and control eyes of each individual using OCTA (Optovue Inc., Fremont, CA, USA). Vessel density (VD) in superficial (SVC) and deep vascular complex (DVC) of macula and radial peripapillary capillary (RPC) were automatically calculated. Parameters of FAZ region including size, perimeter, acircularity index (AI) and foveal vessel density 300 (FD-300) were measured.

Results: VDs of SCV and DVC were significantly lower, especially in affected regions, in BRVO eyes compared with fellow eyes $(P<0.05)$. BRVO affected eyes has larger FAZ size, FAZ perimeter, Al and lower FD-300 compared with fellow eyes (all $P<0.05)$. VD of SVC and FD-300 were lower in fellow eyes compared with normal control eyes $(P<0.05)$. The average vessel density in whole area and peripapillary area in BRVO eyes were significantly lower compared with fellow eyes $(P<0.05)$. VD of inside disc in fellow eyes was lower than normal eyes $(P<0.05)$.

Conclusions: OCTA provided quantitative information of vascular changes in BRVO. FAZ in BRVO eyes showed significant morphological alterations and decreases of VD in surrounding area. Decreases of VD existed not only in SVC and DVC in macular region but also in RPCs in BRVO eyes. Unaffected eyes of unilateral BRVO showed vascular abnormalities in superficial retinal layer, peri-FAZ area and also peripapillary regions.
\end{abstract}

Keywords: Optical coherence tomography angiography, Retinal vasculature, Foveal avascular zone, Radial peripapillary capillary, Branch retinal vein occlusion

\footnotetext{
* Correspondence: yxchenpumch@outlook.com

Department of Ophthalmology, Peking Union Medical College Hospital, Chinese Academy of Medical Sciences, No.1 Shuaifuyuan Wangfujing Dongcheng District, Beijing 100730, China
}

(c) The Author(s). 2020 Open Access This article is licensed under a Creative Commons Attribution 4.0 International License, which permits use, sharing, adaptation, distribution and reproduction in any medium or format, as long as you give appropriate credit to the original author(s) and the source, provide a link to the Creative Commons licence, and indicate if changes were made. The images or other third party material in this article are included in the article's Creative Commons licence, unless indicated otherwise in a credit line to the material. If material is not included in the article's Creative Commons licence and your intended use is not permitted by statutory regulation or exceeds the permitted use, you will need to obtain permission directly from the copyright holder. To view a copy of this licence, visit http://creativecommons.org/licenses/by/4.0/ The Creative Commons Public Domain Dedication waiver (http://creativecommons.org/publicdomain/zero/1.0/) applies to the data made available in this article, unless otherwise stated in a credit line to the data. 


\section{Background}

Retinal vein occlusion (RVO) is a retinal vascular diseases with high prevalence that can cause severe vison loss after diabetic retinopathy [1].

Systemic conditions, especially hypertension, hyperlipidemia and diabetes mellitus have been considered to be predisponding to RVO [2,3]. Retinal vein occlusion can be categorized as central (CRVO), hemi-, and branch retinal vein occlusions (BRVO) based on the veins affected [4]. Fluorescein angiography(FA)is the gold standard for evaluating structural and functional status of retinal vasculature in retinal vascular diseases, especially in diabetic retinopathy and RVO. However, FA is an invasive procedure and it may lead to some side effects [5] such as allergic reaction and nausea. Details of retinal vessels may not be visualized because of dye leakage and pooling. It is also difficult to differentiate retinal vessels by layer, and deeper vasculature tissues are not well presented in FA images. Spectral-domain optical coherence tomography (SD OCT) is a noninvasive and efficient method to evaluate retinal and choroidal structures because of its ability to provide images with high resolution and has been widely used in scientific research and clinical settings. Optical coherence tomography angiography (OCTA), a more recent imaging facility, has enabled researchers to visualize microvascular in different retinal layers and choroid. It also provide us with quantitative information about perfusion status of macular and peripapillary regions. Using OCTA, microvascular changes such as microaneurysms, telangiectasia, retinal capillary nonperfusion and disruption of the foveal avascular zone have been found in RVO [6-8]. Decreased microvascular density in different vessel layers of macula and peripapillary region was also reported with quantitative analysis [8-11].

Recent research about FAZ mainly focused on the enlargement of its size and perimeter in diseased eyes, however, acircularity index (AI) has been proved to be a useful parameter depicting the asymmetry of FAZ area in retinal vascular diseases especially in diabetic retinopathy $[12,13]$. Another quantitative parameter, foveal vessel density 300 (FD-300) is a new metric which evaluates vessel density of the area closely surrounding FAZ. To our knowledge, AI and FD-300 have not been used to evaluate FAZ asymmetry and perfusion states in BRVO patients.

The radial peripapillary capillary (RPC) layer is a delicately organized vasculature radiating from the optic nerve head $(\mathrm{ONH})$ that lies most superficially. Cross sectional studies using OCTA has found a decreased RPC density in retinal vascular diseases, like branch and central retinal artery occlusions [14, 15]. Reports about RPC density from literature failed to differentiate RPCs and other large retinal vessels around the disc [16].
Microvascular changes in area surrounding the disc in patients with unilateral BRVO has not been analyzed thoroughly with quantitatively methods .

In this study, we measured AI and FD-300 as well as RPC density in BRVO eyes and fellow eyes in unilateral BRVO patients and we also compared these parameters between fellow eyes in BRVO patients and control eyes to present a thorough evaluation of microvascular changes in BRVO.

\section{Methods \\ Patients}

Forty-seven eyes of 47 patients with unilateral BRVO who were treated at the Department of Ophthalmology of Peking Union Medical College Hospital (PUMCH), Beijing, China between January 2018 and December 2018 were enrolled in this retrospective observational study. Treatment naïve patients and patients who have been treated with intravitreal medication were included. Patients with poor OCTA images quality (quality index below 5) because of poor eye fixation, media opacities were excluded. Subjects with retinal surgery history, pathologic myopia, ocular trauma, retinal artery occlusion, and other concomitant ocular diseases such as age-related macular degeneration, glaucoma and diabetic retinopathy were also excluded. The exclusion criteria also included eyes with CRVO or hemicentral retinal vein occlusion (HRVO).

One of the control groups consisted of the clinically unaffected fellow eyes of the enrolled subjects if the fellow eye was otherwise healthy without any known ocular diseases or ocular surgical operation. A normal anterior and posterior segment on examination of the eye and a normal intraocular pressure were required. Another control group was made up with 47 age-matched normal individuals who had no history of any ocular diseases or ocular surgical operation. The ophthalmic examination of the normal individuals was unremarkable. One eye of each normal individual was selected randomly as the control eye.

Information including age, sex, duration of disease and best corrected visual acuity (BCVA, logMAR) were obtained from the medical records. Each patients underwent a careful examination including slit lamp-assisted biomicroscopy, intraocular pressure, fluorescein angiography (FA), SD-OCT (Spectralis Heidelberg Engineering, Heidelberg, Germany), and OCTA using the AngioVue OCTA system version 2017.1 (Optovue Inc., Fremont, CA, USA).

\section{Macular microvascular OCTA imaging}

Macular OCT angiograms images were captured using the AngioVue OCTA system version 2017.1 (Optovue Inc., Fremont, CA, USA) with the Angio Retina mode. A 
newly developed 3D projection artifact removal (PAR) algorithm was included in the program. In situ OCTA signal was differentiated from projection artifacts by the software based on the information from OCT and OCTA volume and removes the projection artifacts.

For each eye, a voxel image with a side of $3 \mathrm{~mm}$ centered on the fovea was chosen for analyze. The scanned vascularized tissue was automatically segmented into four enface slabs by the installed Angiovue software based on the default settings: the superficial vascular complex (SVC), the deep vascular complex (DVC), the outer retinal layer, and the choriocapillaris layer. Vascular tissue from the internal limiting membrane to $10 \mu \mathrm{m}$ above the inner plexiform layer (IPL) consisted of the superficial capillary network. The deep capillary network was defined as vasculature from $10 \mu \mathrm{m}$ above the IPL to $10 \mu \mathrm{m}$ below the outer plexiform layer (OPL), no overlap existed between the 2 slabs.

FAZ metrics including size, perimeter, foveal acircularity index(AI), and foveal vessel density 300(FD-300) were evaluated with the software(Table 3). AI is defined as the ratio between the measured perimeter and the perimeter of a circular area of the same size: the closer the shape is to the circle, the closer the value is to 1 . FD-300 is the vessel density in a $300-\mathrm{mm}$ wide area encompassing the FAZ, including both SVC and DVC. FAZ area is excluded in measurement of vessel density in this area, due to its high variability among different individuals. FD-300 is a useful parameter that gives us additional information about vasculature surrounding FAZ area and it has been used in the detection of early signs of diabetic retinopathy in previous studies [17].

\section{Radial peripapillary capillary measurement}

A rectangle scan of $4.5 * 4.5 \mathrm{~mm}$ centered on $\mathrm{ONH}$ was obtained for each eye with AngioVue OCTA system using Angio-Disc mode. The software automatically fits a $2.0 \mathrm{~mm}$ diameter circle, centered on $\mathrm{ONH}$, and defines a circle $2.0 \mathrm{~mm}$ wide that extends from the optic disc as the peripapillary region. The peripapillary area was divided into the following eight regions automatically based on Garway-Heath method [18]: nasal superior (NS), nasal inferior (NI), inferior nasal (IN), inferior temporal (IT). Temporal inferior (TI), temporal superior (TS), superior temporal (ST) and superior nasal (SN). Vessel densities of the whole image, inside disc and each sector of peripapillary area were generated by the software automatically.

The patients were divided into two sub groups based on the location (superior or inferior) of the affected vein and vessel density in each sector of the superficial and deep vascular plexus and RPC were compared in each group.
The automated layer segmentation and FAZ delineation in all scans were reviewed by two independent experts. In case of segmentation errors or FAZ delineation error, the examiners corrected errors manually until agreement achieved.

\section{Statistical analysis}

Statistic analysis was performed by SPSS (SPSS for Mac, version 25.0; IBM/SPSS, Chicago, IL, USA). Continuous variables are sumerized as mean and SD. Paired $t$ test was applied to compare the demographics and evaluate the difference in macular metrics, FAZ parameters and peripapillary vessel densities between BRVO eyes and the contralateral ones. Unpaired $t$ test was applied between contralateral eyes and normal control ones. A two-tailed $P$ value of $<0.05$ as statistically significant.

\section{Results}

Patients' demographic and clinical characteristics

Fifty-seven patients were enrolled primarily, while 10 patients were excluded. Out of the 10 excluded subjects, 7 patients were excluded because the quality of OCTA images were inadequate for analysis, 1 patient was excluded because of lack of FAZ zones in both eyes, 2 patients were excluded due to diabetic retinopathy. Forty-seven eyes of 47 patients $(22$ men) with a mean age of $55.0 \pm$ 11.0 years (median, 55.0 years; range, $25-82$ years) were eventually included in this study. All patients had unilateral involvement. Thirty patients had right-eye involvement and 17 patients had left involvement. The superior temporal branch vein was occluded in 38 patients, the inferior temporal branch vein was occluded in 8 patients, and the superior nasal branch vein was occluded in $1 \mathrm{pa}-$ tient. The mean presenting BCVA was logMAR $0.440 \pm$ 0.324 . The mean duration of the symptoms of BRVO was $8.3 \pm 14.7$ months (0.5-46 months). The mean BCVA for the contralateral eyes was logMAR $0.096 \pm$ 0.143 (Table 1). The foveal retinal thickness was significantly $(P<0.001)$ thicker in BRVO eyes than in the contralateral unaffected eyes. (Table 2). For the normal

Table 1 Demographics and clinical characteristics of patients with BRVO

\begin{tabular}{ll}
\hline Variables & Mean \pm Standard Deviation \\
\hline BRVO eyes & 47 \\
Age, y, mean \pm SD & $55.0 \pm 11.0$ (range, 25-82) \\
Sex, male/female & $22 / 25$ \\
Affected eye, OD/OS & $30: 17$ \\
BCVA of BRVO eyes & $0.440 \pm 0.324$ \\
BCVA of fellow eyes & $0.096 \pm 0.143$ \\
Symptom duration of BRVO & $8.3 \pm 14.7$ (range 0.5-46 months) \\
Superior/inferior, no & $39 / 8$ \\
\hline
\end{tabular}


Table 2 Macular measurements in BRVO eyes and fellow eyes

\begin{tabular}{|c|c|c|c|}
\hline Variables & $\begin{array}{l}\text { Eyes with } \\
\text { BRVO }(n=47)\end{array}$ & $\begin{array}{l}\text { Contralateral } \\
\text { unaffected eyes } \\
(n=47)\end{array}$ & $\begin{array}{l}P \text { value } \\
\text { (paired } t \text { test) }\end{array}$ \\
\hline BCVA & $0.440 \pm 0.324$ & $0.096 \pm 0.143$ & $<0.001$ \\
\hline $\begin{array}{l}\text { Foveal retinal } \\
\text { thickness }(\mu \mathrm{m})\end{array}$ & $321 \pm 113$ & $248 \pm 20$ & $<0.001$ \\
\hline \multicolumn{4}{|c|}{ Vascular density in SVC (\%) } \\
\hline Whole & $40.4 \pm 4.0$ & $45.6 \pm 3.5$ & $<0.001$ \\
\hline Foveal & $15.5 \pm 5.0$ & $15.5 \pm 5.9$ & 0.960 \\
\hline Temporal & $41.3 \pm 5.3$ & $47.3 \pm 3.5$ & $<0.001$ \\
\hline Superior & $42.2 \pm 7.5$ & $50.1 \pm 3.9$ & $<0.001$ \\
\hline Nasal & $42.7 \pm 6.0$ & $47.5 \pm 4.0$ & $<0.001$ \\
\hline Inferior & $44.6 \pm 5.5$ & $49.8 \pm 4.0$ & $<0.001$ \\
\hline \multicolumn{4}{|c|}{ Vascular density in DVC (\%) } \\
\hline Whole & $42.9 \pm 5.0$ & $50.0 \pm 3.0$ & $<0.001$ \\
\hline Foveal & $28.2 \pm 9.3$ & $29.8 \pm 8.0$ & 0.158 \\
\hline Temporal & $44.0 \pm 7.1$ & $52.7 \pm 3.0$ & $<0.001$ \\
\hline Superior & $41.1 \pm 8.8$ & $52.0 \pm 3.6$ & $<0.001$ \\
\hline Nasal & $46.2 \pm 6.4$ & $52.8 \pm 3.2$ & $<0.001$ \\
\hline Inferior & $46.0 \pm 7.4$ & $52.2 \pm 3.8$ & $<0.001$ \\
\hline $\mathrm{FAZ}(\mathrm{mm} 2)$ & $0.394 \pm 0.260$ & $0.325 \pm 0.136$ & 0.046 \\
\hline FAZ perimeter(mm) & $2.589 \pm 1.108$ & $2.255 \pm 0.503$ & 0.031 \\
\hline $\mathrm{Al}$ & $1.23 \pm 0.13$ & $1.14 \pm 0.04$ & $<0.001$ \\
\hline FD-300(\%) & $45.66 \pm 6.04$ & $49.21 \pm 4.46$ & $<0.001$ \\
\hline
\end{tabular}

control group, the mean age was $53.9 \pm 13.03$ years (median, 56.0 years; range, $27-73$ years). The mean BCVA was $\log$ MAR $0.040 \pm 0.116$. The foveal retinal thickness was $248 \pm 19 \mu \mathrm{m}$, not significantly differed from the contralateral unaffected eyes $(P>0.05)$ (Table 3$)$.

\section{Macular vessel density}

Lower vessel density was detected in eyes affected by BRVO in both the SVC $(P<0.05)$ and DVC $(P<0.05)$ compared with the fellow eyes in OCTA images. In the BRVO group, the FAZ is more irregular in shape compared with that in the fellow eyes. The size $(P<0.05)$ and perimeter of FAZ $(P<0.05)$ were significantly larger in BRVO eyes than fellow eyes. The AI was higher $(P<$ $0.05)$ and foveal vessel density 300 was lower $(P<0.05)$ in BRVO eyes compared with the fellow eyes (Table 2). The contralateral eyes showed lower SVC in whole area, especially in temporal area and superior area of macular region $(P<0.05)$, compared with normal control eyes. FD-300 was significantly lower in contralateral unaffected eyes than in normal control eyes $(P<0.05)$ (Table 3).

In sub group analysis, we found vessel density was significantly lower in all sectors $(P<0.05)$ except foveal region in SVC and DVC in eyes with superior vein
Table 3 Macular measurements in contralateral eyes and normal control eyes

\begin{tabular}{|c|c|c|c|}
\hline Variables & $\begin{array}{l}\text { Contralateral } \\
\text { unaffected } \\
\text { eyes }(n=47)\end{array}$ & $\begin{array}{l}\text { Normal control eyes } \\
(n=47)\end{array}$ & $\begin{array}{l}P \text { value } \\
\text { (unpaired } t \text { test) }\end{array}$ \\
\hline BCVA & $0.096 \pm 0.143$ & $0.040 \pm 0.116$ & 0.056 \\
\hline $\begin{array}{l}\text { Foveal retinal } \\
\text { thickness }(\mu \mathrm{m})\end{array}$ & $248 \pm 20$ & $248 \pm 19$ & 0.954 \\
\hline \multicolumn{4}{|c|}{ Vascular density in SVC (\%) } \\
\hline Whole & $45.6 \pm 3.5$ & $47.2 \pm 2.6$ & 0.015 \\
\hline Foveal & $15.5 \pm 5.9$ & $15.6 \pm 6.6$ & 0.963 \\
\hline Temporal & $47.3 \pm 3.5$ & $48.8 \pm 2.9$ & 0.022 \\
\hline Superior & $50.1 \pm 3.9$ & $51.5 \pm 2.8$ & 0.047 \\
\hline Nasal & $47.5 \pm 4.0$ & $48.7 \pm 5.3$ & 0.204 \\
\hline Inferior & $49.8 \pm 4.0$ & $51.1 \pm 3.2$ & 0.094 \\
\hline \multicolumn{4}{|c|}{ Vascular density in DVC (\%) } \\
\hline Whole & $50.0 \pm 3.0$ & $50.5 \pm 3.3$ & 0.451 \\
\hline Foveal & $29.8 \pm 8.0$ & $28.7 \pm 5.5$ & 0.803 \\
\hline Temporal & $52.7 \pm 3.0$ & $53.7 \pm 3.2$ & 0.141 \\
\hline Superior & $52.0 \pm 3.6$ & $53.0 \pm 3.2$ & 0.142 \\
\hline Nasal & $52.8 \pm 3.2$ & $53.9 \pm 2.9$ & 0.090 \\
\hline Inferior & $52.2 \pm 3.8$ & $52.9 \pm 3.9$ & 0.340 \\
\hline $\mathrm{FAZ}(\mathrm{mm} 2)$ & $0.325 \pm 0.136$ & $0.352 \pm 0.090$ & 0.270 \\
\hline $\begin{array}{l}\text { FAZ } \\
\text { perimeter(mm) }\end{array}$ & $2.255 \pm 0.503$ & $2.345 \pm 0.348$ & 0.316 \\
\hline $\mathrm{Al}$ & $1.14 \pm 0.04$ & $1.14 \pm 0.04$ & 0.686 \\
\hline FD-300(\%) & $49.21 \pm 4.46$ & $51.39 \pm 3.56$ & 0.010 \\
\hline
\end{tabular}

occlusion. Vessel density was significantly lower in inferior $(P<0.05)$ and nasal $(P<0.05)$ sectors in SVC and in all sectors except foveal region in DVC in eyes with inferior vein occlusion (Fig. 1).

\section{Peripapillary vessel density}

The average vessel density of the whole, inside disc and peripapillary region were $47.7 \pm 4.0,46.8 \pm 6.2,49.9 \pm 4.2$ in BRVO eyes, and $49.9 \pm 2.3,47.7 \pm 5.6,52.7 \pm 3.0$ in contralateral eyes. BRVO eyes has lower vessel density in whole area and peripapillary area compared with contralateral eyes $(P<0.05)$ (Table 4$)$.

The average vessel density of the whole, inside disc and peripapillary region were $50.7 \pm 1.6,50.7 \pm 5.3$, $53.3 \pm 2.2$ in normal control eyes. The contralateral unaffected eyes has lower VD in whole area and inside disc area of the peripapillary region $(P<0.05)$ (Table 5$)$ compared with normal eyes.

In eyes with superior vein occlusion, vessel density in inferior temporal, temporal superior, superior temporal and superior nasal sectors were significantly lower than contralateral eyes $(P<0.05)$. In eyes with inferior vein occlusion, vessel density in inferior nasal, inferior temporal 


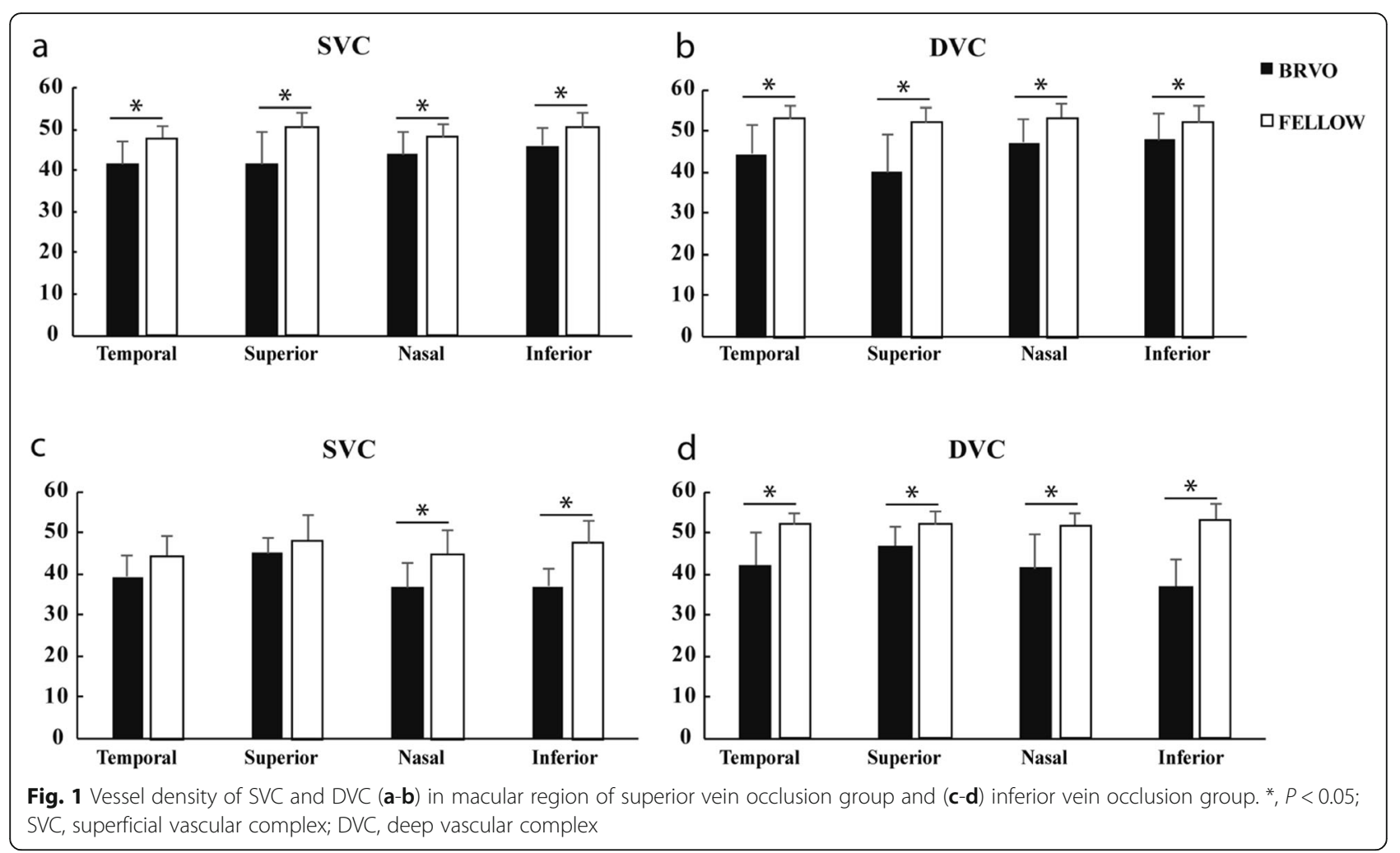

and temporal inferior sectors were significantly lower than contralateral eyes $(P<0.05)$ (Fig. 2).

\section{Discussion}

In this study, we quantified vessel density in macular region using OCTA. Our study revealed that vessel density in BRVO eyes was significantly lower in affected and adjacent sectors in superficial retinal layer and in all

Table 4 Peripapillary vessel density in BRVO eyes and fellow eyes

\begin{tabular}{llll}
\hline Variables & $\begin{array}{l}\text { Eyes with BRVO } \\
(n=47)\end{array}$ & $\begin{array}{l}\text { Contralateral } \\
\text { unaffected eyes } \\
(n=47)\end{array}$ & $P$ value \\
\hline Whole(\%) & $44.7 \pm 4.0$ & $49.9 \pm 2.3$ & $<0.001$ \\
Inside disc(\%) & $46.8 \pm 6.2$ & $47.6 \pm 5.4$ & 0.390 \\
Peripapillary(\%) & $47.8 \pm 5.6$ & $52.8 \pm 3.1$ & $<0.001$ \\
Nasal superior(\%) & $44.1 \pm 5.6$ & $48.9 \pm 4.7$ & 0.159 \\
Nasal inferior(\%) & $47.2 \pm 5.8$ & $47.9 \pm 4.8$ & 0.410 \\
Inferior nasal(\%) & $49.4 \pm 9.1$ & $52.5 \pm 4.2$ & 0.035 \\
Inferior temporal(\%) & $52.9 \pm 9.3$ & $58.4 \pm 4.5$ & $<0.001$ \\
Temporal inferior(\%) & $52.4 \pm 6.4$ & $53.3 \pm 5.0$ & 0.337 \\
Temporal superior(\%) & $54.4 \pm 4.2$ & $56.7 \pm 3.7$ & 0.005 \\
Superior temporal(\%) & $49.0 \pm 7.9$ & $56.6 \pm 4.1$ & $<0.001$ \\
Superior nasal(\%) & $47.4 \pm 7.4$ & $51.3 \pm 4.5$ & $<0.001$ \\
\hline
\end{tabular}

regions but the foveal region in deep retinal layer compared with contralateral unaffected eyes.

The decrease of vessel density in macular region was in accordance to previous studies that applied OCTA to measure vessel densities in retinal vein occlusion patients [7, 19-22]. In a previous BRVO study by Samara's group, vessel densities in macular region were measured by sector and researchers found vessel density in affected sector of BRVO eyes was lower than fellow eyes in both

Table 5 Peripapillary vessel density in contralateral unaffected eyes and normal control eyes

\begin{tabular}{llll}
\hline Variables & $\begin{array}{c}\text { Contralateral } \\
\text { unaffected } \\
\text { eyes }(n=47)\end{array}$ & $\begin{array}{l}\text { Normal control } \\
\text { eyes }(n=47)\end{array}$ & $P$ value \\
\hline Whole(\%) & $49.9 \pm 2.3$ & $50.7 \pm 1.6$ & 0.040 \\
Inside disc(\%) & $47.6 \pm 5.4$ & $50.7 \pm 5.3$ & 0.007 \\
Peripapillary(\%) & $52.8 \pm 3.1$ & $53.2 \pm 2.2$ & 0.467 \\
Nasal superior(\%) & $48.9 \pm 4.7$ & $49.1 \pm 4.0$ & 0.798 \\
Nasal inferior(\%) & $47.9 \pm 4.8$ & $48.7 \pm 4.1$ & 0.394 \\
Inferior nasal(\%) & $52.5 \pm 4.2$ & $53.0 \pm 3.6$ & 0.588 \\
Inferior temporal(\%) & $58.4 \pm 4.5$ & $58.4 \pm 3.5$ & 0.953 \\
Temporal inferior(\%) & $53.3 \pm 5.0$ & $53.7 \pm 3.3$ & 0.642 \\
Temporal superior(\%) & $56.7 \pm 3.7$ & $57.6 \pm 2.6$ & 0.174 \\
Superior temporal(\%) & $56.6 \pm 4.1$ & $56.9 \pm 3.1$ & 0.719 \\
Superior nasal(\%) & $51.3 \pm 4.5$ & $51.2 \pm 4.2$ & 0.855 \\
\hline
\end{tabular}



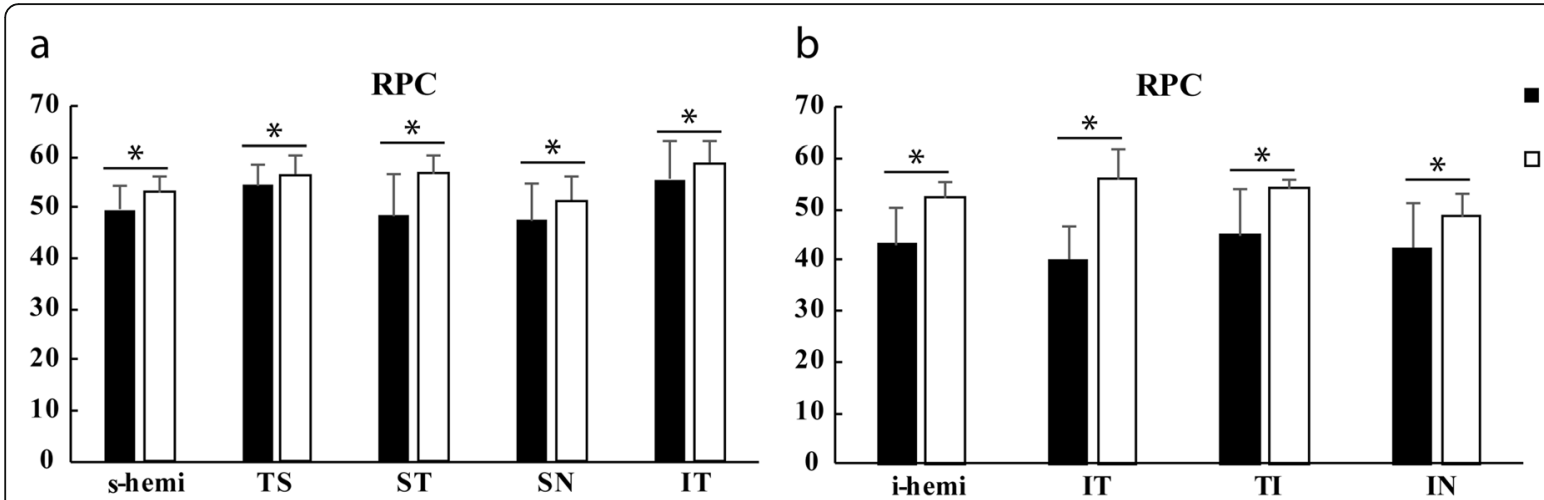

Fig. 2 Vessel density of RPC in a superior vein occlusion group and $\mathbf{b}$ inferior vein occlusion group. RPC, radial peripapillary capillary; s-hemi, superior -hemi; i-hemi, inferior-hemi TS, temporal superior; ST, superior temporal; SN, superior nasal; IT, inferior temporal; TI, temporal inferior; IN, inferior nasal; ${ }^{*}, P<0.05$

superficial and deep network, while vessel density in the unaffected sector of BRVO eyes was also lower than fellow eye in deep network [23]. What's more, affected sector was defined as superior or inferior quadrant of a circular grid in Samara's study, so they only compared superior and inferior sectors in their research. Changes in nasal and temporal regions were not discussed in their work. In the study of Coscas et al. they found that nonperfusion areas were more common in deep capillary plexus [7], suggesting that DCPs were more vulnerable to ischemic attack. Freund et al. discovered that collateral vessels mainly existed in deep vascular complex, supporting a continuous arrangement of superficial and deep vascular complexes and venous drainage through the deep vascular complex [24]. Agreed with previous study, our result suggested DCP was more vulnerable to ischemic changes and BRVO may cause a more extensive vascular alteration.

Recent studies found enlarged FAZ in superficial and deep retinal layer in BRVO eyes [23, 25, 26], which was negatively correlated with visual acuity $[23,25,27]$. In our study, FAZ size and perimeter were larger in BRVO eyes compared with fellow eyes, which agreed with previous reports. Besides, we also found a larger AI and lower FD-300 in BRVO affected eyes in comparison to fellow eyes. Wons et al. measured the angle between the papillomacular plane and the maximum FAZ diameter in RVO eyes and contralateral unaffected eyes and found a significant difference between the two groups. According to their research, a distorted FAZ and an unorganized capillary structure would be a marker in RVO affected eyes [28]. Previous studies has suggested that FAZ size may vary considerably in normal individual and causing a significant overlap among healthy and diseased individuals $[29,30]$, making it difficult to recognize difference between study groups. Recently, a new parameter AI was described by Tam et al. to quantify the irregularity of FAZ [13], which has been proved to be a useful parameter evaluating the asymmetry of the FAZ, providing information about the ischemic status of diseased eyes [12]. Our result agreed with Won's study and showed that BRVO affected eyes are more irregular in shape compared with fellow eyes. This was the first study a, to describe the asymmetry of FAZ in BRVO eyes with AI. Decrease in FD-300 reflects vascular drop out around foveal region and has been proved to be a useful parameter in diabetic retinopathy [17]. No significant differences were detected in foveal vessel density between superficial and deep vessel complex in our study. This could be the caused by the scarcity of vessels in FAZ region. However, when the quantified area skipped FAZ and extend to $300 \mu \mathrm{m}$ area surrounding FAZ, vascular drop out became obvious. A lower vessel density of SVC in contralateral unaffected eyes compared with normal control eyes was another discovery in our study, which agreed with Wang's research [19]. This may suggest that BRVO may be the result of systemic changes in both eyes and vascular drop out may have happened prior to BRVO event. Interestingly, decrease of VD was only found in SVC in contralateral eyes, which also agrees with Wang's result. This may indicate that the underlying mechanism of vascular drop out in contralateral eyes was something other than the blockage of vessels in BRVO eyes. Besides, we also found that FD-300 in contralateral eyes was also lower compared with normal control eyes, while no difference was found regarding AI, FAZ size, and FAZ perimeter between the two groups. This may indicate that vascular drop out around FAZ is sensitive in the contralateral eyes.

Radial peripapillary capillary dropout was another important discovery in our study. Wang et al. measured flow velocity of veins merging from optic disc and found a slower flow velocity in the occluded hemisphere [31]. 
Recent studies found a reduction of peripapillary choroidal thickness in BRVO affected and fellow eyes in unilateral BRVO subjects, suggesting BRVO may be associated with a hypoxic attack to the peripapillary choroid [11,32]. Shin et al. discovered that the peripapillary vessel density and perfusion density were lower in the fellow eyes of unilateral BRVO patients [16], indicating RVO may cause structural abnormality even in fellow unaffected eyes. However, Wang's study only measured large vessels around optic disc while Shin's research measured both large vessels and radial peripapillary capillaries. In our study, we measured radial peripapillary capillaries around optic nerve head with the installed software and found a significant decrease of peripapillary radial peripapillary capillary density in the affected sectors of BRVO eyes. Similar to Shin's research, we also found vascular drop out of peripapillary vessels in contralateral unaffected eyes. However, vascular drop out stands out in the inside disc region, which disagrees with Shin's study. Since we use different apparatus and the area we measured was different, the result could be influenced by these factors. Further study is in need to reveal the most vulnerable area of vascular drop out in peripapillary regions. As far as I know, this is the first report to quantify radial peripapillary capillary change in BRVO affected eyes.

In normal human eyes, blood supply to $\mathrm{ONH}$ is relying on posterior ciliary artery and central retinal artery, which also plays a role in blood supply of superficial RNFL layer of ONH. RPCs are straight, oriented superficial vessels that are paralleled to each other and arched to nourish RNFL around the ONH [33-35]. In the past decades, fluorescein angiography (FA) was used in the evaluation of $\mathrm{ONH}$ perfusion. However, FA requires dye injection and it is difficult to observe RPCs with this traditional method. OCTA shows the advantage for evaluating $\mathrm{ONH}$ perfusion because of its non-invasive nature and high resolution. RPCs can be easily visualized and vascular perfusion status can be quantified within minutes with OCTA. RPC drop out has been reported in glaucoma [36] and diabetes mellitus [37] patients, and has been considered as a useful parameter evaluating vascular dysfunction. Current research has found that mean RPC density was correlated with mean RNFL thickness [34]. Decreasing of RNFL thickness was found with OCT in RVO eyes [32, 38, 39], suggesting retinal nerve fiber atrophy may be the result of RVO as the disease progressed. In our study, PRC was lower in BRVO eyes in comparison to fellow eyes, especially in the affected sectors. However, no significant thinning of RNFL was observed in either the affected sector or the unaffected sector (data not shown), which disagreed with previous studies. This could be explained by the discrepancy of patients included in our research since we included both treatment naïve patients and those who has been treated. ONH swelling is usually observed in treatment naïve patients at the early stage of BRVO and this can influence the average RNFL thickness. However, the underlying swelling of RNFL may have little impact on RPC and the decrease of RPC density was prominent in our research.

Some limitations remains in this research. First, the study is a retrospective study and lacks longitudinal data. A longitudinal study is necessary to elucidate vascular changes with treatments. Besides, there is likely a selection bias because the sample size was limited. In addition, we did not measure vessel density of choriocapillaris in macular and $\mathrm{ONH}$ region. Artifacts such as projection and shadow may influence the accuracy of the measurement of choriocapillaris [40]. We scanned a $3^{*} 3 \mathrm{~mm}^{2}$ area of the foveal and $4.5^{*} 4.5 \mathrm{~mm}^{2}$ area of the $\mathrm{ONH}$ and these regions were relatively small. A larger scanning region with high accuracy may bring out more information of perfusion status. Further studies are needed to provide a thorough status of perfusion and vascular changes in a larger scale in BRVO eyes with the updated OCTA techniques.

\section{Conclusions}

In conclusion, our study demonstrated OCTA with upgraded software enhanced with 3D PAR provides high-resolution images and quantitative information of microvascular parameters of not only macular, but also peripapillary vascular in BRVO eyes. Vascular density of SVC and DVC in macular region was much lower in BRVO eyes compared with fellow eyes. SVC was significantly lower in affected sectors while all sectors in DVC were decreased in affected eyes. In addition to enlarged FAZ area and perimeter, larger AI and lower FD-300 are prominent in BRVO eyes and can be used to evaluate the asymmetry and ischemic status of foveal region. More importantly, lower RPC density was another feature of BRVO affected eyes and RPC density can be a useful parameter to evaluated perfusion status of $\mathrm{ONH}$ in BRVO. Unaffected eyes of unilateral BRVO showed vascular abnormalities in superficial retinal layer, periFAZ area and also peripapillary regions.

\footnotetext{
Abbreviations

RVO: Retinal vein occlusion; FAZ: Foveal avascular zone; ONH: Optic nerve head; VD: Vessel density; SVC: Superficial vascular complex; DVC: Deep vascular complex; RPC: Radial peripapillary capillary; Al: Acircularity index; FD300: Foveal vessel density 300; CRVO: Central retinal vein occlusion; SDOCT: Spectral-domain optical coherence tomography; HRVO: Hemicentral retinal vein occlusion; BCVA: Best corrected visual acuity; FA: Fluorescein angiography; IPL: Inner plexiform layer; OPL: Outer plexiform layer; NS: Nasal superior; NI: Nasal inferior; IN: Inferior nasal; IT: Inferior temporal; TI: Temporal inferior; TS: Temporal superior; ST: Superior temporal; SN: Superior nasal
} 


\section{Authors' contributions}

LLC interpreted data, drafted this manuscript and reviewed the literature. MZY and LS helped design the work. MZY, YLW and LS collected the data. YLW and SL analyzed the data. MZY and YLW revised the manuscript. YXC final approval. All authors have read and approved the final manuscript.

\section{Funding}

Not applicable.

\section{Availability of data and materials}

The datasets presented in this study is available from the corresponding author upon request.

\section{Ethics approval and consent to participate}

The study adhered to the tenets of the Declaration of Helsinki and was approved by PUMCH. Written informed consent was obtained from all subjects (and the parents/guardians of any minors included as participants). The research was approved by the institutional review board of PUMCH (approval number: S-K631)

\section{Consent for publication}

Written informed consents were obtained from all participants for the publication of clinical information and images.

\section{Competing interests}

The authors declare that they have no competing interests.

\section{Received: 20 August 2019 Accepted: 25 March 2020}

\section{Published online: 19 April 2020}

\section{References}

1. Klein R, Klein BE, Moss SE. Meuer SM (2000) the epidemiology of retinal vein occlusion: the beaver dam eye study. Trans Am Ophthalmol Soc. 2000;98: 133-41 discussion 141-3.

2. Jaulim A, Ahmed B, Khanam T, Chatziralli IP. Branch retinal vein occlusion: epidemiology, pathogenesis, risk factors, clinical features, diagnosis, and complications. An update of the literature. Retina. 2013:33(5):901-10.

3. Glacet-Bernard A, Coscas G, Chabanel A, Zourdani A, Lelong F, Samama MM. Prognostic factors for retinal vein occlusion: prospective study of 175 cases. Ophthalmology. 1996;103(4):551-60

4. Jonas J, Paques M, Mones J, Glacet-Bernard A. Retinal vein occlusions. Dev Ophthalmol. 2010;47:111-35.

5. Kwiterovich KA, Maguire MG, Murphy RP, Schachat AP, Bressler NM, Bressler $S B$, et al. Frequency of adverse systemic reactions after fluorescein angiography - results of a prospective-study. Ophthalmology. 1991;98(7): 1139-42.

6. Suzuki N, Hirano Y, Yoshida M, Tomiyasu T, Uemura A, Yasukawa T, et al. Microvascular abnormalities on optical coherence tomography angiography in macular edema associated with branch retinal vein occlusion. Am J Ophthalmol. 2016;161:126-32.e1.

7. Coscas F, Glacet-Bernard A, Miere A, Caillaux V, Uzzan J, Lupidi M, et al. Optical coherence tomography angiography in retinal vein occlusion: evaluation of superficial and deep capillary plexa. Am J Ophthalmol. 2016; 161:160-71.e1-2.

8. Seknazi D, Coscas F, Sellam A, Rouimi F, Coscas G, Souied EH, et al. Optical coherence tomography angiography in retinal vein occlusion: correlations between macular vascular density, visual acuity, and peripheral nonperfusion area on fluorescein angiography. Retina. 2018;38(8):1562-70.

9. Koulisis N, Kim AY, Chu Z, Shahidzadeh A, Burkemper B, Olmos de Koo LC, et al. Quantitative microvascular analysis of retinal venous occlusions by spectral domain optical coherence tomography angiography. PLoS One. 2017;12(4):e0176404

10. Wakabayashi T, Sato T, Hara-Ueno C, Fukushima Y, Sayanagi K, Shiraki N, et al. Retinal Microvasculature and visual acuity in eyes with branch retinal vein occlusion: imaging analysis by optical coherence tomography angiography. Invest Ophthalmol Vis Sci. 2017;58(4):2087-94.

11. Lee NE, Kang HM, Choi JH, Koh HJ, Lee SC. Sectoral changes of the peripapillary choroidal thickness in patients with unilateral branch retinal vein occlusion. Int J Ophthalmol. 2019;12(3):472-9.

12. Krawitz BD, Mo S, Geyman LS, Agemy SA, Scripsema NK, Garcia PM, et al. Acircularity index and axis ratio of the foveal avascular zone in diabetic eyes and healthy controls measured by optical coherence tomography angiography. Vis Res. 2017;139:177-86.

13. Tam J, Dhamdhere KP, Tiruveedhula P, Manzanera S, Barez S, Bearse MA Jr, et al. Disruption of the retinal parafoveal capillary network in type 2 diabetes before the onset of diabetic retinopathy. Invest Ophthalmol Vis Sci. 2011;52(12):9257-66.

14. Baumal CR. Optical coherence tomography angiography of retinal artery occlusion. Dev Ophthalmol. 2016;56:122-31.

15. Bonini Filho MA, Adhi M, de Carlo TE, Ferrara D, Baumal CR, Witkin AJ, et al. Optical coherence tomography angiography in retinal artery occlusion. Retina. 2015;35(11):2339-46.

16. Shin YI, Nam KY, Lee SE, Lim HB, Lee MW, Jo YJ, et al. Changes in Peripapillary Microvasculature and retinal thickness in the fellow eyes of patients with unilateral retinal vein occlusion: an OCTA study. Invest Ophthalmol Vis Sci. 2019:60(2):823-9.

17. Yasin Alibhai A, Moult EM, Shahzad R, Rebhun CB, Moreira-Neto C, McGowan M, et al. Quantifying microvascular changes using OCT angiography in diabetic eyes without clinical evidence of retinopathy. Ophthalmol Retina. 2018:2(5):418-27.

18. Garway-Heath DF, Poinoosawmy D, Fitzke FW, Hitchings RA. Mapping the visual field to the optic disc in normal tension glaucoma eyes. Ophthalmology. 2000;107(10):1809-15.

19. Wang Q, Chan SY, Yan Y, Zhou W, Jonas JB, et al. Optical coherence tomography angiography in retinal vein occlusions. Graefes Arch Clin Exp Ophthalmol. 2018;256(9):1615-22

20. Kang JW, Yoo R, Jo YH, Kim HC. Correlation of microvascular structures on optical coherence tomography angiography with visual acuity in retinal vein occlusion. Retina. 2017:37(9):1700-9.

21. Glacet-Bernard A, Sellam A, Coscas F, Coscas G, Souied EH. Optical coherence tomography angiography in retinal vein occlusion treated with dexamethasone implant: a new test for follow-up evaluation. Eur J Ophthalmol. 2016;26(5):460-8.

22. Adhi M, Filho MA, Louzada RN, Kuehlewein L, de Carlo TE, Baumal CR, et al. Retinal capillary network and Foveal avascular zone in eyes with vein occlusion and fellow eyes analyzed with optical coherence tomography angiography. Invest Ophthalmol Vis Sci. 2016;57(9): OCT486-94.

23. Samara WA, Shahlaee A, Sridhar J, Khan MA, Ho AC, Hsu J. Quantitative optical coherence tomography angiography features and visual function in eyes with branch retinal vein occlusion. Am J Ophthalmol. 2016;166:76-83.

24. Freund KB, Sarraf D, Leong BCS, Garrity ST, Vupparaboina KK, Dansingani KK. Association of optical coherence tomography angiography of collaterals in retinal vein occlusion with major venous outflow through the deep vascular complex. JAMA Ophthalmol. 2018;136:1262-70.

25. Casselholmde Salles M, Kvanta A, Amren U, Epstein D. Optical coherence tomography angiography in central retinal vein occlusion: correlation between the Foveal avascular zone and visual acuity. Invest Ophthalmol Vis Sci. 2016;57(9):OCT242-6

26. Winegarner A, Wakabayashi T, Hara-Ueno C, Sato T, Busch C, Fukushima Y, et al. Retinal microvasculature and visual acuity after intravitreal aflibercept in eyes with central retinal vein occlusion: an optical coherence tomography angiography study. Retina. 2018;38(10):2067-72.

27. Balaratnasingam C, Inoue M, Ahn S, McCann J, Dhrami-Gavazi E, Yannuzzi $L A$, et al. Visual acuity is correlated with the area of the Foveal avascular zone in diabetic retinopathy and retinal vein occlusion. Ophthalmology. 2016;123(11):2352-67.

28. Wons J, Pfau M, Wirth MA, Freiberg FJ, Becker MD, Michels S. Optical coherence tomography angiography of the Foveal avascular zone in retinal vein occlusion. Ophthalmologica. 2016:235(4):195-202.

29. Chui TY, VanNasdale DA, Elsner AE, Burns SA. The association between the foveal avascular zone and retinal thickness. Invest Ophthalmol Vis Sci. 2014; 55(10):6870-7.

30. Hilmantel G, Applegate RA, van Heuven WA, Stowers SP, Bradley A, Lee BL. Entoptic foveal avascular zone measurement and diabetic retinopathy. Optom Vis Sci. 1999;76(12):826-31.

31. Wang Y, Fawzi AA, Varma R, Sadun AA, Zhang X, Tan O, et al. Pilot study of optical coherence tomography measurement of retinal blood flow in retinal and optic nerve diseases. Invest Ophthalmol Vis Sci. 2011:52(2):840-5.

32. Kang HM, Choi JH, Koh HJ, Lee CS, Lee SC. Significant reduction of Peripapillary Choroidal thickness in patients with unilateral branch retinal vein occlusion. Retina. 2018;38(1):72-8. 
33. Mansoori T, Sivaswamy J, Gamalapati JS, Agraharam SG, Balakrishna N. Measurement of radial Peripapillary capillary density in the Normal human retina using optical coherence tomography angiography. J Glaucoma. 2017; 26(3):241-6.

34. Mansoori T, Sivaswamy J, Gamalapati JS, Balakrishna N. Topography and correlation of radial peripapillary capillary density network with retinal nerve fibre layer thickness. Int Ophthalmol. 2018;38(3):967-74.

35. Scoles D, Gray DC, Hunter JJ, Wolfe R, Gee BP, Geng Y, et al. In-vivo imaging of retinal nerve fiber layer vasculature: imaging histology comparison. BMC Ophthalmol. 2009;9:9.

36. Mastropasqua R, Agnifili L, Borrelli E, Fasanella V, Brescia L, Di Antonio L, et al. Optical coherence tomography angiography of the Peripapillary retina in Normal-tension Glaucoma and chronic Nonarteritic anterior ischemic optic neuropathy. Curr Eye Res. 2018;43(6):778-84.

37. Cao D, Yang D, Yu H, Xie J, Zeng Y, Wang J, et al. Optic nerve head perfusion changes preceding peripapillary retinal nerve fibre layer thinning in preclinical diabetic retinopathy. Clin Exp Ophthalmol. 2019;47(2):219-25.

38. Kim CS, Shin KS, Lee HJ, Jo YJ, Kim JY. Sectoral retinal nerve fiber layer thinning in branch retinal vein occlusion. Retina. 2014;34(3):525-30.

39. Lim HB, Sung JY, Ahn SI, Jo YJ, Kim JY. Retinal nerve Fiber layer thickness in various retinal diseases. Optom Vis Sci. 2018;95(3):247-55.

40. Ghasemi Falavarjani K, Al-Sheikh M, Akil H, Sadda SR. Image artefacts in swept-source optical coherence tomography angiography. Br J Ophthalmol. 2017:101(5):564-8

\section{Publisher's Note}

Springer Nature remains neutral with regard to jurisdictional claims in published maps and institutional affiliations.

Ready to submit your research? Choose BMC and benefit from:

- fast, convenient online submission

- thorough peer review by experienced researchers in your field

- rapid publication on acceptance

- support for research data, including large and complex data types

- gold Open Access which fosters wider collaboration and increased citations

- maximum visibility for your research: over $100 \mathrm{M}$ website views per year

At $\mathrm{BMC}$, research is always in progress.

Learn more biomedcentral.com/submissions 